\title{
IMPLEMENTASI MEDIA JERSEY BERANGKA DALAM MENINGKATKAN HASIL BELAJAR MENGURUTKAN BILANGAN DI MADRASAH IBTIDAIYAH
}

\author{
Nur Nafisatul Fithriyah', Anisatul Karimah², Khusnul Mu'alifah ${ }^{3}$ \\ ${ }^{1}$ STAI Luqman AL Hakim Surabaya \\ Email: nurnafisatulfithriyah@gmail.com \\ ${ }^{2}$ Universitas Islam Negeri Sunana Ampel Surabaya \\ Email: karimahanisatul16@gmail.com \\ ${ }^{3}$ Universitas Islam Negeri Sunana Ampel Surabaya \\ Email: Khusnulmualifah54@gmail.com
}

\begin{abstract}
Abstrak
Penelitian ini secara umum untuk meningkatkan hasil belajar mengurutkan bilangan melalui media jersey berangka pada siswa kelas II MI Miftahul Ulum. Penelitian kali ini menggunakan penelitian tindakan kelas, dalam penelitian ini terdapat dua siklus yang terdiri dari perencanaan, pelaksanaan, pengamatan dan refleksi. Teknik pengumpulan data yang digunkan adalah observasi, tes, dan dokumentasi. Observasi yang dilakukan tentang keaktifan siswa dan aktivitas guru, tes yang digunakan menggunakan tes tulis, dan dokumentasi adalah foto selama penelitian. Hasil dari penelitian tindakan kelas diperoleh bahwa media jersey berangka dapat meningkatkan hasil belajar siswa, pada siklus I hasil belajar siswa $42,85 \%$ (6 siswa yang tuntas) dan $57,15 \%$ (8 siswa yang tuntas) sedangkan pada siklus II 85,72\% (12 siswa yang tutas) dan 14,28 (2 yang belum tuntas), sehingga siswa mencapai kriteria ketuntasan minimal yang telah ditentukan, dan keaktifan siswa dalam proses pembelajaran mengalami peningkatan. Dalam menggunakan media pada saat kegiatan belajar mengajar dapat meningkatkan kemauan siswa untuk terus belajar, dengan menggunakan media proses pembelajaran tidak hanya berpusat pada guru tetapi juga melibatkan siswa.
\end{abstract}

\section{Kata kunci: Media jersey berangka, Hasil belajar, dan Madrasah Ibtidaiyah}

\begin{abstract}
This research in general, this research is to improve learning outcomes of sorting numbers through numbered jersey media for second grade students of MI Miftahul Ulum. This research uses classroom action research, in this study there are two cycles consisting of planning, implementation, observation and reflection. Data collection techniques used are observation, tests, and documentation. Observations were made about student activity and teacher activity, the tests used were written tests, and documentation was photos during the research. The results of the classroom action research showed that the numbered jersey media could improve student learning outcomes, in the first cycle the student learning outcomes were $42.85 \%$ (6 students who completed) and $57.15 \%$ (8 students who completed) while in the second cycle it was $85.72 \%$ (12 students who complete) and 14.28 (2 who have not completed), so that students achieve the minimum criteria for completeness that have been determined, and student activity in the learning process has increased. Using media during teaching and learning activities can increase students' willingness to continue learning, by using media the learning process is not only teacher-centered but also involves students.
\end{abstract}

Keywords: Framed jersey media, learning outcomes, and Islamic elementary school 


\section{Pendahuluan}

Pola umum kegiatan pengajaran adalah terjadinya interaksi antara guru dengan anak didik dengan bahan sebagai perantaranya. Guru yang mengajar, anak didik yang belajar. Maka guru adalah orang yang menciptakan lingkungan belajar bagi kepentingan belajar anak didik. Anak didik adalah orang yang digiring ke dalam lingkungan belajar yang telah diciptakan oleh guru. Gaya mengajar guru mempengaruhi gaya belajar siswa (Djamarah \& Zain, 2006, pp. 114-115). Gaya mengajar guru mempengaruhi cara belajar siswa, maka dari itu dalam mengajar guru harus lebih kreatif agar proses belajar mengajar tidak monoton. Pendidikan di tingakat Sekolah Dasar (SD) merupakan pendidikan tahap awal dalam jenjang pendidikan nasional, penanaman konsep pada tingkat dasar inilah harus lebih dalam dan kuat agar peserta didik mempunyai bekal yang sangat kuat untuk memasuki ke jenjang yang lebih tinggi. Dalam tingkat SD ada beberapa mata pelajaran yang ditempuh oleh anak didik, diantaranya adalah mata pelajaran Matematika.

Menurut Dikmenum, dalam (Taniredja, 2013, p. 66) Matematika berasal dari bahasa latin manthanein atau mathema yang berarti balajar atau hal yang dipelajari. Matematika dalam bahasa Belanda disebut wiskunde atau ilmu pasti, yang kesemuanya berkaitan dengan penalaran. Ciri utama matematika adalah penalaran deduktif, yaitu kebenaran suatu konsep atau pernyataan diperoleh sebagai akibat logis dari kebenaran sebelumnya sehingga kaitan antar konsep atau pernyataan dalam matematika bersifat konsisten. Belajar matematika merupakan suatu proses untuk memahami suatu materi tentang matematika harus memahami materi sebelumnya. Karena dalam pembelajaran matematika memerlukan tahapan-tahapan dari hal yang lebih mudah menuju yang lebih sulit. (Firmansyah, 2015, pp. 36-37)

Matematika merupakan ilmu yang mempunyai peran penting untuk memajukan daya pikir manusia. Matematika juga merupakan mata pelajaran pokok dan wajib yang ada di setiap jenjang pendidikan. Karena mata pelajaran matematika begitu penting, maka konsep dasar yang diajarkan kepada siswa haruslah benar dan kuat. Namun sampai saat ini terbentuk kesan umum bahwa mata pelajaran matematika merupakan mata pelajaran yang sangat sulit, bahkan ada sebagian siswa beranggapan mata pelajaran 
matematika adalah pelajaran yang sangat menyebalkan. Akan tetapi tidak sedikit pula banyak siswa yang berprestasi baik tingkat nasional ataupun internasional karena kemahirannya dalam mata pelajaran matematika. Matematika identik dengan angka, bilangan, dan rumus-rumus yang banyak membuat anak didik merasa malas untuk menghafakalan rumus-rumus dalam materi, kebanyakan siswa cepat menanggapi dan menghafal rumus-rumus, tapi ketika sudah naik ke tingkat atau kelas selanjutnya, apa yang telah ditanggapi dan dihafal semuanya menjadi hilang.

Hasil observasi yang peneliti lakukan di Madrasah Ibtidaiyah Miftahul Ulum Sumenep Madura, peneliti mengamati saat proses pembelajaran berlangsung banyak siswa yang masih kurang memahami atau kurang paham terhadap materi yang disampaikan guru, siswa tidak terlibat langsung dalam proses pembelajaran karena siswa hanya mendengarkan penjelasan guru. Hal itu berpengaruh terhadap hasil belajar siswa. Masalah lain yang terjadi dalam proses belajar mengajar adalah cara mengajar guru yang monoton dan tidak memakai media pembelajaran dalam jangka waktu yang lama, sehingga anak didik cepat merasa bosan dan tidak bersemangat dalam kelas, juga tidak memberikan kesempatan kepada siswa untuk mengeluarkan pendapat dan menemukan ide yang baru, sehingga Kriteria Ketuntasan Minimal (KKM) belum tercapai. Hal tersebut nampak dari hasil ulangan harian matematika dimana sejumlah 14 siswa yang tuntas hanya 6 siswa dan yang tidak tuntas 8 siswa.

Media adalah apa saja yang dapat menyalurkan informasi dari sumber informasi kepada penerima informasi. Jadi, media pembelajaran merupakan perangkat lunak yang berupa pesan atau informasi pendidikan yang disajikan menggunakan sutau peralatan bantu. Keberadaan media pembelajaran sebagai alat bantu dalam proses pembelajaran merupakan suatu kenyaatan yang tidak dapat dipungkiri. Guru sebagai penyampai pesan memeliki kepentingan yang besar untuk memudahkan tugasnya dalam menyampaikan pesan atau materi pembelajaran kepada peserta didik. Guru harus menyadari bahwa materi pembelajaran akan sulit untuk dicerna oleh siswa tanpa adanya media pembelajaran, apalagi materi yang akan dipelajari tergolong materi yang rumit dan kompleks. (Muhson, 2010, pp. 2-3) 
Matematika merupakan mata pelajaran yang membutuhkan media pembelajaran yang nyata yang dapat dilihat langsung oleh siswa, seperti pada mata pelajaran matematika kelas II SD/MI materi mengurutkan bilangan, guru tidak hanya berceramah saja. Akan tetapi guru dapat menggunakan media jersey berangka untuk meningkatkan hasil belajar siswa dalam mengurutkan bilangan. Berdasarkan masalah yang telah ditemukan di $\mathrm{MI}$ Miftahul Ulum, peneliti akan melakukan perbaikan dengan menggunakan media pembelajaran jersey berangka. Media jersey berangka ini sangat mudah didapat karena terbuat dari kertas karton yang bergambarkan kaos jersey

\section{Metode Penelitian}

Metode penelitian yang digunakan adalah Penelitian Tindakan kelas (PTK). Sebelum melakukan penelitian, peneliti harus merencanakan tindakan apa yang akan dilakukan. Setelah rencana disusun baru peneliti dapat melaksanakan tindakan. Pada saat tindakan dilakukan peneliti melakukan pengamatan pada

proses pembelajaran. Berdasarkan hasil pengamatan yang diperoleh barulah peneliti melakukan refleksi. Jika hasil refleksi menunjukkan perlunya perbaikan, maka tindakan dilakukan lagi dari awal dengan melihat kekurangan yang terjadi pada siklus sebelumnya. (Arikunto, 2015, p. 42)

Penelitian dilakukan di MI Miftahul Ulum Sumenep Madura. Terlebih, khususnya kepada bagaimana penerapan media jersey berangka itu sendiri. Penelitian terfokus pada penerapan media jersey berangka dalam kegiatan belajar siswa kelas II MI Miftahul Ulum Sumenep Madura. Adapun pengumpulan data dilakukan dengan tiga cara yaitu observasi atau kegiatan mengamati terhadap pelaksanaan pembelajaran menggurutkan bilangan di MI Miftahul Ulum Sumenep Madura, tes tulis kepada siswa, dan dokumentasi.

\section{Hasil dan Pembahasan}

Belajar adalah suatu aktivitas atau suatu proses untuk memperoleh pengetahuan, meningkatkan keterampilan, memperbaiki prilaku, sikap, dan mengkokohkan kepribadian. Dalam konteks menjadi tahu atau proses memperoleh pengetahuan, menurut pemahaman sains konvensional, kontak manusia dengan alam diistilahkan dengan pengalaman

(experience). Pengalaman yang terjadi berulang kali 
ISSN 2548-9119

melahirkan pengetahuan, (knowledge), atau a body of knowledge. Definisi ini merupakan definisi umum dalam pembelajaran sains secara konvensional, dan beranggapan bahwa pengetahuan sudah terserak dialam, tinggal bagaimana siswa atau pembelajar bereksplorasi, menggali dan menemukan kemudian memungutnya untuk memperoleh pengetahuan. (Suyono \& Hariyanto, n.d., p. 9) Peningkatan hasil belajar yang baik tidak hanya didukung oleh kemauan siswa untuk belajar dengan baik, namun penggunaan metode pembelajaran yang digunakan oleh guru juga berpengaruh terhadap hasil belajar siswa. (Firosalia, 2016, p. 91)

Menurut Bloom dalam (Suprijono, 2010, p. 6), hasil belajar mencakup kemampuan kognitif, afektif, dan psikomotorik. Proses kognitif yang paling banyak dijumpai dalam tujuantujuan di bidang pendidikan yaitu (1) mengingat berarti mengambil pengetahuan dari memori jangka panjang (2) memahami adalah mengkonstruk makna dari materi pembelajaran, termasuk apa yang diucapkan, ditulis, dan digambar oleh guru (3) mengaplikasikan adalah menerapkan atau menggunakan suatu prosedur dalam keadaan tertentu (4) menganalisis adalah memecah-mecah materi jadi bagian-bagian penyusunnya dan menentukan hubungan-hubungan antar bagianbagian tersebut dan keseluruhan struktur atau tujuan (5) mengevaluasi adalah mengambil keputusan berdasarkan kriteria dan/atau standar (6) mencipta adalah memadukan bagian-bagian untuk membentuk sesuatu yang baru dan koheren atau untuk membuat suatu produk yang orisinil (Anderson \& Krathwol, 2010, pp. 43-45) Domain efektif adalah receiving (sikap menerima), responding (memberikan respon), valuing (nilai), organization (organisasi), characterization (karakteristik). Domain psikomotor meliputi initiatory, pre-routine, dan rountinized.(Suprijono, 2010, pp. 6-7) Pembelajaran matematika merupakan pembelajaran dimana kebenaran suatu konsep atau pernyataan dalam matematika bersifat konsisten dan bukan pengetahuan sendiri. Untuk menerapkan pembelajaran matematika membutuhkan media yang konkrit yang sesuai dengan materi pembelajaran. Media pembelajaran adalah segala sesuatu yang dapat menyalurkan pesan, dapat merangsang fikiran, perasaan, dan kemauan peserta 
didik sehingga dapat mendorong terciptanya proses belajar pada peserta didik (Mudlofir, 2013, p. 111). Menurut Gagne' dan Briggs dalam (Arsyad, 2014, p. 4) media pembelajaran meliputi alat yang secara fisik digunakan untuk menyampaikan isi materi pengajaran, yang terdiri dari antara lain buku, tape recorder, kaset, video camera, video recorder, film, slide (gambar bingkai), foto, gambar, grafik, televisi, dam komputer. Dengan menggunakan media apa yang akan disampaikan guru terhadap siswa akan lebih mudah, dan siswa dalam menanggapi materi yang disampaikan atau materi yang akan dipelajari akan menjadi lebih mudah pula. Media pembelajaran jersey berangka tergolong media yang sederhana karena terbuat dari potongan kertas karton yang bergambarkan seperti kaos jersey yang bertuliskan angka. Manfaat penggunaan media jersey berangka adalah agar kemampuan dan pemahaman dalam mengurutkan bilangan pada siswa meningkat.

Dari hasil data yang diperoleh dari pengamatan yang telah dilakukan pada siklus I yang difokuskan pada materi mengurutkan bilangan menggunakan media jersey berangka masih belum maksimal karena hal ini karena masih belum terbiasa menggunakan media dalam pembelajaran, karena proses pembelajaran yang selama ini siswa dapat hanya mendengarkan penjelasan materi. Hasil observasi keaktifan siswa pada siklus I diperoleh persentase $59,47 \%$. Sedangkan hasil tes hasil belajar siswa pada siklus I terdapat 6 siwa atau sekitar (42,85\%) yang mengalamai ketuntasan dan 8 siswa atau sekitar $(57,15 \%)$ yang belum tuntas. Maka dengan demikian dapat disimpulkan bahwa pembelajaran pada siklus I yang menerapkan media jersey berangka belum maksimal karena masih banyak kegiatan yang belum dilaksanakan. Dan selain itu hasil belajar yang diukur melalui tes menunjukkan hasil yang rendah sehingga pembelajaran pada siklus I memerlukan perbaikan dan dilanjutkan ke siklus II.

Hasil analisis terhadap pelaksanaan pembelajaran menggunakan media jersey berangka pada siklus II secara umum menunjukkan perubahan yang signifikan, kemampuan memahami materi mengurutkan bilangan lebih meningkat, dengan partisipasi siswa dalam pembelajaran yang semakin meningkat, suasana kelaspun menjadi hidup dan lebih menyenangkan. Dari analisi hasil tes yang diberika kepada 
siswa saat pembelajaran siklus II terdapat 12 siswa $(85,72 \%)$ yang tuntas dan 2 siswa $(14,28 \%)$ yang tidak tuntas. Sehingga dapat dikatakan bahwa proses pembelajaran pada siklus II berhasil dan memenuhi indikator keberhasilan yang telah ditentukan, dan peneliti tidak perlu melakukan penelitian ke siklus berikutnya. Sedangkan berdasarkan hasil observasi keaktifan siswa pada siklus II berdasarkan persentase adalah $75 \%$.

Berdasarkan hasil yang diperoleh dari penelitian di MI Miftahul Ulum Kambingan Timur-Saronggi, maka dapat dikatakan bahwa dengan menggunakan media jersey berangka pada materi mengurutkan bilangan kelas II dapat meningkatkan hasil belajar dan kemampuan meyelesaikan soal-soal. Sedangkan hasil dari observasi keaktifan siswa siklus I adalah 59,46\% dan pada siklus II adalah 75\% maka dari itu keaktifan siswa dari siklus I ke siklus II mengalami peningkatan pula. Adapun peningkatan proses pembelajaran antara siklus I dan siklus II dapat dilihat pada tabel berikut :

Tabel 1 peningkatan dari siklus I ke siklus II

\begin{tabular}{|l|l|l|l|}
\hline Keterangan & Siklus I & Siklus II & Peningkatan \\
\hline Keaktifan siswa & $59,46 \%$ & $75 \%$ & $15,54 \%$ \\
\hline Hasil belajar siswa & $57,15 \%$ & $85,72 \%$ & $28,57 \%$ \\
\hline
\end{tabular}

\section{Kesimpulan}

Penerapan media jersey berangka pada mata pelajaran Matematika materi mengurutkan bilangan kelas II berjalan dengan lancar, meskipun terdapat beberapa kendala, tetapi kendala tersebut dapat teratasi dengan baik, sehingga proses selama penelitian berlangsung dengan baik pula.

Pada saat proses penelitian berlangsung observasi keaktifan siswa pada siklus I diperoleh persentase
$59,46 \%$ dan pada siklus II diperoleh persentase $75 \%$. Dan yang ketiga, melalui penerapan media jersey berangka pada mata pelajaran Matematika materi mengurutkan bilangan kelas II dapat meningkatkan hasil belajar siswa, terbukti dengan hasil belajar pada siklus I (57,15\%) dan pada siklus II mengalami peningkatan menjadi $(85,72 \%)$ 


\section{Daftar Pustaka}

Anderson, L. W., \& Krathwol, D. R. (2010). Kerangka Landasan Untuk Pembelajaran, Pengajaran dan Asesmen. Pustaka Pelajar.

Arikunto, S. (2015). Penelitian Tindakan Kelas. Bumi Aksara.

Arsyad, A. (2014). Media Pembelajaran. PT. Raja Grafindo Persada.

Djamarah, S. B., \& Zain, A. (2006). Strategi Belajar Mengajar. PT Rineka Cipta.

Firmansyah, D. (2015). Pengaruh Strategi Pembelajaran dan Minat Belajar Terhadap Hasil Belajar Matematika. Jurnal Pendidikan Unsika, 03(01). https://journal.unsika.ac.id/index.php/judika/article/view/199

Firosalia, K. (2016). Analisis Model Pembelajaran Discovery Learning Dalam Meningkatkan Hasil Belajar Ipa-Biologi. Jurnal Pendidikan Dasr Perkhasa, 2. https://doi.org/https://doi.org/10.31932/jpdp.v2i1.25

Mudlofir, A. (2013). Bahan Ajar Pendidikan dan Latihan Profesi Guru Sertifikasi Guru/Pengawas dalam Jabatan Kuota 2013. Lembaga Pendidikan dan Tenaga Kependidikan Fakultas IImu Tarbiyah dan Keguruan IAIN Sunan Ampel Surabaya.

Muhson, A. (2010). PENGEMBANGAN MEDIA PEMBELAJARAN BERBASIS TEKNOLOGI INFORMASI. Jurnal Pendidikan Akuntansi Indonesia, 8(2). https://doi.org/10.21831/jpai.v8i2.949

Suprijono, A. (2010). Cooperatif Learning. Pustaka Pelajar.

Suyono, \& Hariyanto. (n.d.). Belajar dan Pembelajaran. PT. Remaja Rosdakarya.

Taniredja, T. (2013). Penelitian Tindakan Kelas Untuk Pengembangan Profesi Guru Praktik, Praktis, dan Mudah. CV. Alfabeta. 